istic globules of an amorphous material which are resistant to diastase and positive for periodic-acid-Schiff. Immunofluorescence studies have shown that these globules are immunologically similar to alpha ${ }_{1}$-antitrypsin; they may be the result of accumulation of a precursor of alpha ${ }_{1}$-antitrypsin which cannot be released from the hepatocytes possibly because of a modification in its structure. The material extracted from the globules contains no sialic acid-part of the circulating alpha $a_{1}$-antitrypsin molecule. ${ }^{3}$

The association between deficiency of alpha ${ }_{1}$-antitrypsin and childhood cirrhosis was first described in $1976^{4}$ and since confirmed in numerous studies in both children and adults. In childhood, liver disease associated with alpha $\mathrm{i}_{\mathbf{i}}$-antitrypsin deficiency usually presents in the first four months of life as an acute hepatitis with conjugated hyperbilirubinaemia and often follows directly neonatal physiological jaundice. The characteristic periodic-acid-Schiff-positive globules within the hepatocytes are rarely seen before 12 weeks of age, despite florid liver damage. ${ }^{5}$ The clinical severity of the hepatitis is variable. About one-quarter of the children presenting with neonatal hepatitis die from cirrhosis by the second decade of life, one-quarter have cirrhosis, one-quarter have persistently abnormal liver function values, and one-quarter seem to recover completely. ${ }^{6}$ Not all PiZ infants develop clinical features of neonatal hepatitis. A comprehensive epidemiological study in Sweden found that $11 \%$ of infants with

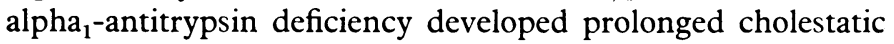
jaundice; $6 \%$ had subclinical hepatitis in infancy without jaundice; and $35 \%$ had minor abnormalities of liver function. ${ }^{7}$ Why only some PiZ infants develop liver disease is not known. Possibly the liver is unable to control a damaging process caused by environmental or associated genetic factors, which would have been adequately controlled had normal inhibitors of bacterial, viral, or inflammatory cell proteases been present.

In adults the association between the homozygous $\mathrm{ZZ}$ phenotype and liver disease is even less clear, and the incidence of such an association varies considerably. ${ }^{8}$ Furthermore, there are appreciable differences in the prevalence of hepatic fibrosis, cirrhosis, or hepatocellular carcinoma in different geographical areas. ${ }^{10-13}$

Whether an association exists between liver disease and the heterozygous $\mathrm{PiZ}$ state remains uncertain. No association was found when patients were screened by measuring serum levels of alpha -antitrypsin $^{13}$ or by phenotyping the patients. ${ }^{1415}$ In contrast, an association was seen when only patients with the characteristic periodic-acid-Schiff-positive inclusions in the hepatocytes were studied. ${ }^{16}$ Hodges et al ${ }^{17}$ have recently reported the results of a five-year prospective study of liver biopsy specimens from 1055 adults with liver disease. Phenotyping of the 34 patients whose specimens contained characteristic hepatocyte inclusions showed phenotype $M Z$ in 25 of them. The other phenotypes found were $Z Z$, SZ, MS, and MM. Twenty-one per cent of patients with cryptogenic cirrhosis and $20.5 \%$ of those with chronic active hepatitis negative for hepatitis B surface antigen had phenotype $M Z$, whereas this was found in only $3.5 \%$ of patients with alcoholic cirrhosis and $2 \cdot 6 \%$ of those with other types of cirrhosis. Hodges $e t a l^{17}$ also suggested that the patients with chronic active hepatitis and phenotype $M Z$ might have distinctive clinical features.

The mechanism of liver damage in such patients remains to be explained. It does not seem to be correlated with low serum activities of alpha $a_{1}$-antitrypsin; $42 \%$ of the heterozygous patients with chronic active hepatitis or cryptogenic cirrhosis reported by Hodges et al had values within the normal range at presentation. Nor is the damage likely to result from accumulation of alpha ${ }_{1}$-antitrypsin in the liver, since patients without liver damage have periodic-acid-Schiff-positive globules. Further studies from different geographical areas are needed to find out whether there is a true association between the PiMZ phenotype and liver disease or whether liver damage is secondary to unknown associated environmental or genetic factors.

${ }^{1}$ Pierce JA, Eradio B, Dew TA. Antitrypsin phenotypes in St Louis. $\mathcal{F} A M A$ $1975 ; 231: 609-12$.

Talamo RC, Langley CE, Reed CE, Makino S. $\propto$-Antitrypsin deficiency: a variant with no detectable $\alpha_{1}$-antitrypsin. Science $1973 ; 181: 70-1$.

${ }^{3}$ Jeppsson J-O, Larsson C, Eriksson S. Characterization of $\alpha_{1}$-antitrypsin in the inclusion bodies from the liver in $\alpha_{1}$-antitrypsin deficiency. $N$ Engl f Med $1975 ; 293: 576-9$.

- Sharp HL. The current status of $\alpha_{1}$-antitrypsin, a protease inhibitor, in gastrointestinal disease. Gastroenterology $1976 ; 70: 611-21$.

Talbot IC, Mowat AP. Liver disease in infancy: histological features and relationship to $\alpha_{1}$-antitrypsin phenotype. 7 Clin Pathol $1975 ; 28 \cdot 559-63$.

' Psacharopoulos HT, Mowat AP, Cook JJL, Rodeck C. Familial factors and the severity of liver disease in genetic deficiency of alpha-1-antitrypsin (PiZZ). British Paediatric Association, 53rd annual meeting, York. Arch Dis Child (in press).

' Sveger T. Liver disease in alpha ${ }_{1}$-antitrypsin deficiency detected by screening of 200000 infants. N Englf Med 1976;294:1316-21.

${ }^{8}$ Berg NO, Eriksson S. Liver disease in adults with alpha ${ }_{1}$-antitrypsin deficiency. N Engl F Med 1972;287:1264-7.

Triger DR, Millward-Sadler GH, Czaykowski AA, Trowell J, Wright R.

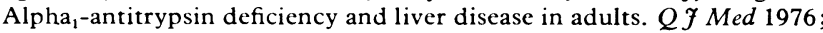
45:351-72.

${ }^{10}$ Lieberman J. Emphysema, cirrhosis, and hepatoma with alpha $\mathbf{1}_{1}$-antitrypsin deficiency. Ann Intern Med $1974 ; 81: 850-2$.

11 Palmer PE, Wolfe HJ. $\alpha_{1}$-Antitrypsin deposition in primary hepatic carcinoma. Arch Pathol Lab Med 1976;100:232-6.

12 Kueppers F, Dickson ER, Summerskill WHJ. Alpha ${ }_{1}$-antitrypsin phenotypes in chronic active liver disease and primary biliary cirrhosis. Mayo Clin Proc 1976;51:286-8.

13 Fisher RL, Taylor L, Sherlock S. $\alpha$-1-Antitrypsin deficiency in liver disease: the extent of the problem. Gastroenterology 1976;71:646-51.

14 Morin T, Martin J-P, Feldmann G, Rueff B, Benhamou J-P, Ropartz C.

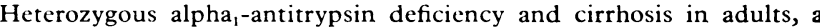
fortuitous association. Lancet $1975 ; \mathrm{i}: 250-1$

${ }^{15}$ Theodoropoulos G, Fertakis A, Archimandritis A, Kapordelis C, Angel-

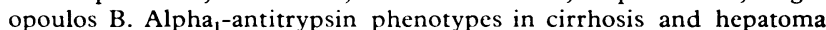
Acta Hepatogastroenterol (Stuttg) 1976;23:114-7.

16 Eriksson S, Moestrup T, Hägerstrand I. Liver, lung and malignan disease in heterozygous (PiMZ) $\alpha$-antitrypsin deficiency. Acta Med Scand 1975;198:243-7.

17 Hodges JR, Millward-Sadler GH, Barbatis C, Wright R. Heterozygous $\mathrm{MZ}$ alpha $\mathrm{a}_{1}$-antitrypsin deficiency in adults with chronic active hepatitis and cryptogenic cirrhosis. N Englf Med 1981 ;304:557-60.

\section{Treatment of seasonal and perennial rhinitis}

Hyperreactivity of the nasal mucosa causes a range of disorders whose main symptoms are sneezing, itching, rhinorrhoea, nasal congestion, and blockage. These symptoms are usually labelled as seasonal or perennial allergic rhinitis when there is a recognised provoking antigen and as vasomotor (or nonallergic) rhinitis when there is not. Since some patients with seasonal allergic rhinitis (hay fever) may have nasal symptoms all the year these disorders may prove to be a continuum rather than separate diseases. ${ }^{1}$

Allergic rhinitis, whether seasonal or perennial, is mainly due to a type 1 allergic reaction. Specific IgE immunoglobulins become attached to the surface of the mast cells, and when the patient is re-exposed to the antigen these cells release histamine and other chemical mediators, causing sneezing, nasal itching, rhinorrhoea, and nasal congestion. Effective treatment depends on either preventing the release of mediators or blocking their pharmacological effects.

In contrast, the mechanisms underlying vasomotor and 
non-allergic rhinitis are not fully understood. Among the factors that may be concerned are, firstly, stimulation of cholinergic receptors ("autonomic imbalance"), which renders the nasal mucosa hyperreactive to non-specific stimuli (such as cold air, chemical irritants, and dust); secondly, type 3 allergy; and, finally, other non-immunological reactions such as sensitivity to salicylates and indomethacin. In these cases treatment is largely empirical.

When an allergic aetiology is proved or appears likely on clinical grounds the initial management should be directed at controlling the allergens-simple in theory but often a problem in practice. Household pets should be removed when these are the source of antigen. House dust and the house-dust mite are more difficult problems, but attempts should be made to minimise dust, especially in bedrooms. Avoidance of exposure to pollen is virtually impossible, but air filtration is a useful means of controlling pollen exposure indoors, though costly.

Topical treatment is preferable to systemic drug administration in the management of rhinitis since a useful therapeutic effect can be obtained with minimum side effects. Disodium cromoglycate is the only drug available for the treatment of rhinitis which prevents degranulation of the mast cells. It is administered intranasally in powder or as a $2 \%$ solution. Reports of its use in seasonal and perennial allergic rhinitis and conjunctivitis since 1970 have mostly described a good clinical response but additional treatment has often been required. The main disadvantage of treatment with cromoglycate is that it needs to be given four times a day. Topical sympathomimetic (alpha-agonist) agents are effective in relieving nasal congestion but should be reserved for acute infective rhinitis, since their prolonged use is associated with rebound hyperaemia, local irritation, and, finally, rhinitis medicamentosa. Topical steroid preparations (such as beclomethasone dipropionate or flunisolide) are especially effective in seasonal allergic rhinitis, but they have also proved beneficial in allergic and non-allergic perennial rhinitis. There is a clear dose-response effect. Most patients require $400 \mu \mathrm{g}$ beclomethasone daily to induce improvement, though the maintenance dose may be lower than this. Nasal polyps tend to shrink during treatment with topical steroids but this is no substitute for surgical polypectomy. Topical beclomethasone has no real adverse effects apart from minor nasal bleeding in fewer than one in 20 users, ${ }^{2}$ and systemic absorption of the steroids is negligible. Eye symptoms are unaffected by nasal application of beclomethasone and require separate management.

Oral drugs which have been used in the treatment of rhinitis include $\mathrm{H}_{1}$-receptor antagonists (antihistamines), sympathomimetics, and steroids. Antihistamines antagonise the action of histamine released by mast cells, but their anticholinergic effects have an important subsidiary action. They relieve sneezing, rhinorrhoea, nasal itch, and conjunctivitis but have little effect on nasal obstruction. Used mainly in seasonal allergic rhinitis, they are most effective if administered before antigen exposure. Their use is limited by the high incidence of adverse effects: sedation is the main problem and is potentiated by alcohol and other central nervous system depressants. In allergic rhinitis symptoms are often most troublesome at night and on rising in the morning, and sustained-release antihistamine preparations taken at night may be effective in controlling the symptoms and avoid daytime drowsiness. ${ }^{3}$ Anticholinergic effects (dry mouth, constipation, and difficulty with micturition) may also be troublesome. Since there is some evidence that the therapeutic effects (measured by weal-andflare response) are much longer than the half lives of these drugs ${ }^{4}$ administration once or twice daily may control symptoms and reduce unwanted effects. Two newer antihistamines, astemizole and terfenadine, seem free of sedative effects at doses which adequately antagonise the $\mathrm{H}_{1}$-receptor ${ }^{5-7}$ and are under evaluation.

Oral decongestant sympathomimetics (such as pseudoephedrine and phenylpropanolamine) are available alone or in combination tablets with antihistamines-a combination which has been shown to have a synergistic effect. ${ }^{8}$ Nevertheless, oral sympathomimetics should be prescribed with care since an appreciable rise in blood pressure has been reported in even young normotensive individuals ${ }^{9}$ and interactions may occur with adrenergic-neurone-blocking antihypertensive drugs, monoamine-oxidase inhibitors, indomethacin, ${ }^{10}$ and a combination of methyldopa and oxprenolol. ${ }^{11}$ Treatment with oral steroids should be reserved for patients with severe symptoms uncontrolled by conventional topical treatment. The potentially serious adverse effects should limit use of steroids to short periods only and at doses not exceeding $10 \mathrm{mg}$ of prednisolone daily. Depot injections of methylprednisolone are considered valuable treatment by some doctors, but they probably give no better results than equivalent doses of oral prednisolone. Treatment by injection has two advantages, however: it allows medical staff to control treatment on an intermittent basis and so avoids manipulation of treatment by the patient; and highdose, short-duration treatment often produces rapid symptomatic relief which may outlast the pharmacological effects of the injection. In some patients who respond poorly to topical steroids a course of oral steroids or a single depot injection may establish whether the rhinitis is sensitive or resistant to steroids.

Immunotherapy (hyposensitisation) should be reserved for patients with a clearly defined allergy in whom exposure to the antigen is unavoidable and where other treatment has failed, since the treatment carries a risk of provoking anaphylaxis. It has been used particularly in seasonal and perennial rhinitis due to pollens and house-dust mite. Symptoms are usually reduced by about half, but the duration of benefit is unknown.

When medical treatment has failed specific types of nasal obstruction (deviated septum or enlarged turbinates) can be relieved by surgical techniques. Patency of the nasal passages will be improved but usually incompletely. In severe cases of watery rhinorrhoea, removal of most of the parasympathetic innervation of nasal mucosa by sectioning the Vidian nerve may be effective, though the surgical technique is difficult. Nasal polyps and recurrent sinusitis often occur in patients with seasonal or perennial rhinitis, and these problems, too, may need surgical management.

${ }^{1}$ Hendeles L, Weinberger $M$, Wong L. Medical management of noninfectious rhinitis. Am $\mathcal{F}$ Hosp Pharm 1980;37:1496-504.

${ }^{2}$ Mygind N. Nasal allergy. Oxford: Blackwell Scientific Publications, 1978.

${ }^{3}$ Nicholson AN. Effect of the antihistamines brompheniramine maleate and triprolidine hydrochloride on performance in man. Br f Clin Pharmacol $1979 ; 8: 321-4$.

4 Cook TJ, MacQueen DM, Wittig HJ, Thornby JI, Lantos RL, Virtue CM. Degree and duration of skin test suppression and side effects with antihistamines. F Allergy Clin Immunol 1973;51:71-7.

5 Clarke C.H, Nicholson AN. Performance studies with antihistamines. $\mathrm{Br} \mathcal{F}$ Clin Pharmacol 1978;6:31-5.

${ }^{6}$ Kulrestha VK, Gupta PP, Turner P, Wadsworth J. Some clinical pharmacological studies with terfenadine, a new antihistamine drug. $\mathrm{Br} \mathcal{F} \mathrm{Clin}$ Pharmacol 1978;6:25-9.

7 Nicholson AN, Stone BM. Performance studies in man with the $\mathbf{H}_{\mathbf{1}}$ histamine receptor antagonists, astemizole and terfenadine. $\mathrm{Br} \mathscr{f}$ Pharmacol (in press).

${ }^{8}$ Aschan G. Decongestion of nasal mucous membranes by oral medication in acute rhinitis. Acta Otolaryngol (Stockh) 1974;77:433-8.

${ }^{9}$ Horowitz JD, Lang WJ, Howes LG, et al. Hypertensive responses induced by phenylpropanolamine in anorectic and decongestant preparations. Lancet $1980 ;$ i:60-1. 
${ }^{10}$ Lee KY, Beilin LJ, Vandongen R. Severe hypertension after ingestion of an appetite suppressant (phenylpropanolamine) with indomethacin Lancet 1979 ; i:1110-1.

${ }^{11}$ McLaren EH. Severe hypertension produced by interaction of phenylpropanolamine with methyldopa and oxprenolol. Br Med f 1976;ii: 283-4.

\section{NHS reorganisation: some hazards for doctors}

On 1 April 1982193 district health authorities will be taking over the running of the NHS in England from 90 area health authorities. Scotland, ${ }^{1}$ Wales, ${ }^{2}$ and Northern Ireland ${ }^{3}$ each has its own NHS reorganisation plans, which do not include the formation of districts, and separate timetables. For England, the Secretary of State for Social Services has, after consultation, decided on the district boundaries for the reorganised Health Service and he is now appointing chairmen. The appointment of staff has been delayed because the National Whitley Council's Reorganisation Committee took longer than expected to agree on terms for the staff affected by reorganisation. ${ }^{4}$ But appointments will soon be taking place, and the BMA, as well as warning its divisions to take an active part in the reorganisation, ${ }^{5}$ has also urged doctors to ensure that "it really is patients first in the new NHS." In particular, consultants in the new district management teams have been asked by $\mathrm{Mr} \mathrm{D}$ E Bolt, chairman of the Central Committee for Hospital Medical Services, to look "very critically at proposals for purely administrative posts at district level." One of the Government's aims in the reorganisation is to save money$£ 30 \mathrm{~m}$ is the target-and to use these administrative savings to improve patient care. Administrators may be sceptical of any oversimplification of the problems of slimming such a complex institution as the NHS, ${ }^{6}$ but those NHS staff dealing with patients' clinical needs will be disappointed if the changes turn out to be a game of administrative musical chairs and the savings illusory.

Many doctors will not be personally affected by reorganisation, but for some doctors in community medicine this will be the second time in a decade that their professional lives will have been disrupted. ${ }^{7}$ Given the recruitment difficulties in community medicine, it is unlikely that there will be unemployment in this craft. Even so, the next few months will be a worrying time for these doctors, and to acquaint the new DHA chairmen with the tasks of community physicians the Central Committee for Community Medicine has just sent them an explanatory booklet, ${ }^{8}$ which among other things declares that "no district will require less than two community physicians (the district medical officer and one other) to provide the essential services." The CCCM's next sentence, that "this should be regarded as a minimum" (the committee's italics), would seem to be an unremarkable statement of the obvious were it not for the genuine concern among community physicians that some DHAs might confine their appointments to the one district medical officer defined among the seven "prescribed" management posts in the reorganisation circular. ${ }^{9}$ All other appointments will be at the discretion of the authorities, and community medicine doctors will be looking for support from their colleagues in the profession to ensure that this branch of medicine is appropriately staffed in the reorganised service.

Consultants, for their part, will welcome their colleagues' support in another unresolved issue in reorganisation: the siting of the consultants' contracts. In Patients First ${ }^{10}$ the DHSS proposed that contracts should be held by DHAs: the BMA strongly opposed this, arguing that they should be held at region, which is where all but teaching hospital consultants' contracts are held at present. No final decision has been made, and presumably the Government hopes that by deferring one until the DHAs are set up the switch could be quietly introduced by individual health authorities, who will understandably see a district-held contract as being administratively tidy and a boost to their power. But consultants will not meekly give way, because they regard this issue as one that affects standards of care.

The arguments for retaining contracts at region are powerful. One of the NHS's successes has been the countrywide provision of a good standard of hospital care. This has largely been a result of regional planning, which includes control over the appointment of consultants. Districts might well adopt a parochial or even a political stance, both in deciding the range of local consultant services and in the consultant appointments themselves. This could hinder the promised expansion of the consultant grade, prove needlessly contentious and uneconomic, and create unacceptable variations in standards of hospital care. A substantial proportion of consultants will have duties extending beyond a single district, so the proposed change would mean either introducing complicated administrative arrangements for sharing contracts between DHAs-several in the case of regional specialties-or requiring individual consultants to hold several small-session contracts. Finally, senior staff in RHAs have developed the knowledge and experience to handle two sensitive aspects of consultant employment-discipline and the sick doctor-and in general they have won the respect and confidence of the profession. District staff would have to acquire this experience, and because they would be responsible for many fewer consultants might not achieve the level of skill now available at regional level. This would be detrimental to the NHS at a time when patients show an increasing tendency to complain about their treatment.

On 28 July the Secretary of State for Social Services told Parliament that he had received over 800 representations on the question of consultant contracts being held at region, mostly from individuals or groups of consultants. Given the reluctance of working doctors to participate personally in medicopolitics, this represents a formidable strength of feeling among consultants. The BMA's Annual Representative Meeting at Brighton also showed the strength of the profession's feelings by voting overwhelmingly in favour of contracts being held by RHAs. The new Secretary of State, $\mathrm{Mr}$ Norman Fowler, should waste no time in endorsing that policy decision by the profession.

${ }^{1}$ Scottish Home and Health Department. Structure and management of the NHS in Scotland. 1981(Gen)14. Edinburgh: SHHD, 1981.

2 Anonymous. $\mathrm{Br} \mathrm{Med} \mathcal{F} 1981 ; \mathbf{2 8 3}: 86$.

3 Anonymous, $\mathrm{Br} \mathrm{Med} \mathcal{F} 1981 ; \mathbf{2 8 3}: 86$.

4 Department of Health and Social Security. NHS reorganisation: implementation of General Whitley agreements. London: DHSS, 1981.

${ }^{5}$ British Medical Association. The BMA division in the new Health Service. London: BMA, 1981.

${ }^{6}$ Anonymous. Hippocratic humbug. Health and Social Service fournal 1981 ; 4 September:1065.

${ }^{7}$ Miles DPB. Community physicians and NHS reorganisation in England. Br Med f $1981 ; 283: 743-4$.

${ }^{8}$ Central Committee for Community Medicine. Community medicine at district in the re-organised NHS 1981-1982. London: British Medical Association, 1981.

${ }^{9}$ Department of Health and Social Security. Health Service development structure and management. HC(80)8. London: DHSS, 1980.

10 Department of Health and Social Security. Patients first. London: HMSO, 1979. 